\title{
Thoracic Intraspinal Meningioma
}

National Cancer Institute

\section{Source}

National Cancer Institute. Thoracic Intraspinal Meningioma. NCI Thesaurus. Code C5297.

A meningioma that arises from the meninges of the thoracic region of the spinal cord. 